\title{
Effect of Ultrasonic Irradiation on Preparation and Properties of Ionogels
}

\author{
Yogendra Lal Verma, Manish Pratap Singh, and Rajendra Kumar Singh \\ Ionic Liquid and Solid State Ionics Laboratory, Department of Physics, Banaras Hindu University, Varanasi 221005, India \\ Correspondence should be addressed to Rajendra Kumar Singh, rksingh_17@rediffmail.com
}

Received 22 August 2011; Revised 25 October 2011; Accepted 29 October 2011

Academic Editor: Jaetae Seo

Copyright ( $) 2012$ Yogendra Lal Verma et al. This is an open access article distributed under the Creative Commons Attribution License, which permits unrestricted use, distribution, and reproduction in any medium, provided the original work is properly cited.

\begin{abstract}
Silica-gel matrices containing ionic liquid (IL) 1-butyl-3-methylimidazolium hexafluorophosphate viz. ionogels have been synthesized using one-pot nonhydrolytic sol-gel method and taking tetraethyl orthosilicate (TEOS) as starting precursor. Effect of ultrasonic irradiation on pore parameters of ionogels and vibrational properties of the IL upon confinement in the porous matrix has been investigated. The synthesized gels have been characterized by BET, DSC, TGA, and FTIR. BET analysis shows some changes in the pore parameters due to ultrasonic irradiation. DSC results indicate shift in glass transition temperature upon confinement of the IL. The FTIR spectra show changes in vibrational bands on confinement, particularly, the bands related to the imidazolium ring; aliphatic chain and anion $\mathrm{PF}_{6}{ }^{-}$of the IL are found to shift upon confinement in porous silica matrix obtained due to ultrasonic irradiation. Ultrasonic irradiation has been found to affect the gelation dynamics and kinetics and pore parameters.
\end{abstract}

\section{Introduction}

Ionic liquids are novel materials, which are self-dissociating and composed of organic cations and inorganic/organic anions of varying size [1-7]. Due to dissociated ionic species, ILs have high ionic conductivity. Besides high ionic conductivity, ILs have low vapour pressure, large electrochemical window, high thermal stability, high chemical stability, wide liquidus range and good capability of dissolving various organic/inorganic materials. Low vapour pressure of ILs attracted the attention of chemists in order to develop less polluting chemical processes for synthesis. Recently, high ionic conductivity is attractive from the point of view of its application in electrochemical devices (like batteries, fuel cells, super capacitors, electrochemical solar cells, and electrochromic devices [8-12], etc.). However, its use gets limited due to liquidus nature which results in difficulties such as packaging, leakage and portability. Dai et al. [13] for the first time introduced ionic liquid in porous silica gels. Subsequently, these materials were termed as "ionogel". Now, the ionogels are being extensively investigated by many researchers $[14,15]$. The ionogels are suitable candidates for applications in many devices such as fuel cell, electrochemical sensor, biosensor, and catalysis, and as optical solvent, biocatalysis [15]. The very nature of ionogels involves entrapment of IL in nanopores. According to IUPAC classification, based on pore diameter $(d)$, porous materials are grouped into three classes: (a) microporous, $d<2 \mathrm{~nm}$; (b) mesoporous, $2 \mathrm{~nm}<d<50 \mathrm{~nm}$; (c) macroporous, $d>50 \mathrm{~nm}$ [16]. When IL goes into confined geometry of matrix pore, since IL molecules are big, if the size of the $\mathrm{IL} \approx 9 \AA$ (estimated from gauss-view) is of the order of pore size [14], confinement is likely to change their properties significantly. Therefore, many attempts have been made to study IL in confined geometry. The confinement involves the following. (i) Matrix pore size [17]. (ii) Pore wall surface decoration/functionalization [18]. (iii) Type of matrix: like oxide matrices $\mathrm{SiO}_{2}, \mathrm{SnO}_{2}$, and so forth, or mesoporous conducting matrices of silver, single wall carbon nanotubes, multiwall carbon nanotubes, and so forth [19]. The properties in oxide and conducting porous matrices change differently because of the difference in the nature and extent of IL-pore wall interaction. (iv) Some common ILs with imidazolium and pyridinium cations with different 
anions. Most studies of ILs in confined geometry are focused on the imidazolium-based cations [19-24]. In our earlier experimental and theoretical studies on $[\mathrm{BMIM}]\left[\mathrm{PF}_{6}\right]$, we found that the cation ring gets weakly attached to the silica gel surface oxygen leading to changes in melting point, fluorescence, and vibrational bands [25]. It may be noted that all the studies listed above including our study [18-25] were on ILs with small anions. More recently, we have studied the IL with large anion size [BMIM] $\left[\mathrm{OcSO}_{4}\right]$ and have proposed a phenomenological model to qualitatively account for the anion size dependence of melting point depression [14]. Pore parameters are found to be the function of IL loading. We feel that, apart from these factors, ultrasonic irradiation may affect the pore parameters and other parameters of the matrix. With this view in mind, we have studied the effect of ultrasonic irradiation on pore parameters of the silica-gel matrix containing IL. We have monitored the effect of ultrasound irradiation on changes in the following properties of IL in confined geometry: pore parameters (namely, porosity, pore size distribution, nitrogen sorption characteristic, surface area and pore volume), cation ring related vibrations, aliphatic chain $\mathrm{C}-\mathrm{H}$ vibrations, and vibrations of anion.

Since the rates of chemical reactions such as hydrolysis and condensation in the sol-gel processes are very important to synthesize the different microstructure of gels, different methods have been used to control sol-gel processes. Ultrasonic irradiation can be used to control the gelation dynamics and kinetics of gelation process. The effect of ultrasound on chemical reaction in the sol-gel process is mainly due to acoustic cavitation, which includes three discrete stages: nucleation, bubble growth, and implosive collapse. If ultrasound wave is used, rapid compression of gas during cavitational collapse leads to nearly adiabatic heating due to slow thermal transport, thereby forming localized hotspot and bond cleavage or rearrangement cause, followed by atomic and radical recombination and thermal and chemical quenching [26-28].

The gels prepared by ultrasonic treatment are also called "sonogels". The sonogels have properties which differ from those of the gels prepared without ultrasonic irradiation. However, no study of the effect of ultrasound on the synthesis of ionic liquid confined in silica matrix (ionogels) has been reported. In the present study, the effect of ultrasound irradiation on gelation and subsequent properties of ionogels has been reported. To the best of our knowledge, this is first study conducted to see the effect of ultrasonic irradiation on pore parameters of ionogels.

\section{Materials and Methods}

2.1. Chemical. The ionic liquid [BMIM] $\left[\mathrm{PF}_{6}\right]$ and TEOS were procured from Sigma-Aldrich (numerical prescribed purity) and used as received except for vacuum pre-drying and heating. The other chemical, that is, formic acid (GR grade) was purchased from Merck, Germany.

2.2. Synthesis of IL-Confined Porous Silica Gel. IL-confined porous silica gels (ionogels) have been prepared using one-pot nonhydrolytic sol-gel method. tetraethyl orthosilicate (TEOS) as sol-gel precursor was mixed with formic acid and IL ([BMIM] $\left.\left[\mathrm{PF}_{6}\right]\right)$ at a TEOS/HCOOH/IL molar ratio of $1 / 8 / 0.4$. Care was taken in handling of IL so that it does not come in contact with ambient humidity (handled under dry nitrogen atmosphere). Further, before use, the samples were heated at a temperature of $100^{\circ} \mathrm{C}$ for 12 hours and vacuumdried at a pressure of $10^{-3}$ Torr for 6 hours to remove traces of water. The gel was finally vacuum-dried. Ionic-liquidconfined silica gel of $\mathrm{SiO}_{2}+65 \mathrm{wt} \%$ IL was prepared. It was observed that the silica gel matrix containing $65 \mathrm{wt} \%$ of the IL gets gelated in 40 minute, while upon ultrasonic irradiation, gelation time reduced considerably. Monoliths were aged at casting temperature for 15 days.

We have used low and high power continuous wave sources for the ultrasonic irradiation of the sols. Power output of low power continuous ultrasonic source (frequency $10 \mathrm{MHz}$ ) was $10 \mathrm{~m}$ watts while the power output of the high power ultrasonic source (frequency $20 \mathrm{KHz}$ ) is 120 watts. Ionic liquid, metallic precursor, and formic acid were taken in the specially designed reaction vessel in the proportion mentioned above. Resulting sol was exposed to ultrasonic irradiation. The following three samples have been prepared:

Sample 1\# IG: without ultrasonic irradiation,

Sample 2\# IG1: low power ultrasonic irradiation,

Sample 3\# IG2: high power ultrasonic irradiation.

The reaction vessel used for ultrasonic irradiation consisted of a double-walled metallic (stainless steel) jacket having inlet and outlet assembly for circulating thermostatic fluid. At the bottom of the cylindrical vessel, a quartz crystal of frequency $10 \mathrm{MHz}$ was fitted which, when excited by radio waves of same frequency, generated ultrasonic waves. These waves passed through the sample. The assembly for the high power ultrasonicator consisted of Vibronics Ultrasonicator having $20 \mathrm{KHz}$ transducer.

\subsection{Characterization Methods}

2.3.1. Pore Analysis. Surface area, pore volume, and pore size were measured by BET (Brunauer-Emmett-Teller) method at $77 \mathrm{~K}$ on a Gemini V $2390 \mathrm{t}$ from Micromeritics Instrument Corporation (reproducibility of the system is $\pm 0.01 \%$, and the molecular size of the adsorptive gas $\left(\mathrm{N}_{2}\right)=0.162 \mathrm{~nm}^{2}$ at $77 \mathrm{~K}[16])$. Before the measurements were carried out, IL was extracted by dissolving the gel ingot in acetone $\left(\right.$ at $60^{\circ} \mathrm{C}$ ) and washing several times then subjecting to vacuum drying. After drying, samples were degassed under the flow of $\mathrm{N}_{2}$ at $60^{\circ} \mathrm{C}$ for $25 \mathrm{hr}$ for BET analysis.

2.3.2. Thermogravimetric Analysis (TGA). The thermogravimetric analysis was done using a Mettler Toledo TGA/DSC 1 (degree of accuracy is $\pm 0.3 \mathrm{~K}$ ) at heating rate $10^{\circ} \mathrm{C} / \mathrm{min}$ under $\mathrm{N}_{2}$ atmosphere, and the samples for TGA/DSC measurements were put in $\mathrm{Al}_{2} \mathrm{O}_{3}$ pans. Each sample was also dried at $80-90^{\circ} \mathrm{C}$ for $5 \mathrm{~h}$ before the TGA measurement.

2.3.3. Differential Scanning Calorimetry (DSC). Measurements of glass transition temperatures of the samples 
TABLE 1: Specific surface area, pore volume, pore diameter, and porosity of monolithic silica samples.

\begin{tabular}{lcccc}
\hline Sample name & Average pore diameter $(\mathrm{nm})$ & Pore volume $\left(\mathrm{cm}^{3} / \mathrm{g}\right)$ & BET surface area $\left(\mathrm{m}^{2} / \mathrm{g}\right)$ & $\%$ Porosity \\
\hline \#IG & 11.8 & 1.3 & 299 & 74 \\
\#IG1 & 14.8 & 1.4 & 251 & 75.5 \\
\#IG2 & 22.6 & 1.6 & 182 & 78 \\
\hline
\end{tabular}

were carried out on a Mettler Toledo DSC-1 (with degree of accuracy $\pm 0.02 \mathrm{~K}$ ). The samples were placed in $40 \mu \mathrm{L}$ hermetically sealed aluminum pan with pinhole at the top of the pan, the samples inside the DSC furnace were exposed to a flowing $\mathrm{N}_{2}$ atmosphere. Before the DSC measurement test, each sample was dried at $80^{\circ} \mathrm{C}$ for $5 \mathrm{hr}$.

2.3.4. Fourier Transform Infrared (FTIR) Spectra. The FTIR spectra were recorded using Perkin Elmer spectrum 65 FTIR spectrometer with $0.5 \mathrm{~cm}^{-1}$ resolution. The solid $\mathrm{SiO}_{2}$ : IL composite was dispersed in $\mathrm{KBr}$ and pelletised for recording the spectra of various $\mathrm{SiO}_{2}$ :IL samples. For recording the spectra of IL (neat), a drop of IL was used to wet the $\mathrm{KBr}$ pellet.

\section{Results and Discussion}

The gelification occurred in 40 minutes when no ultrasonic irradiation was done, in 35 minutes, when sol was irradiated with low power ultrasonic wave, while gelification occurred in 25 minutes upon passage of high power ultrasonic waves in the sol. Possibly, the passage of ultrasound wave allows sol-gel particles to approach each other more easily without large electrostatic barriers which enhances the rate of condensation. Apart from the rate of condensation (or rate of gelation), the size of pores also depends upon ultrasonic irradiation. The sol-gel processes may have improved upon ultrasonic irradiation. Figure 1 shows the radial contraction of gel (without ultrasonication) with time. From the Figure 1, it can be seen that for initial few hours (approx. $50 \mathrm{hrs}$ ), radial contraction occurred at a rapid rate, while after $50 \mathrm{hrs}$ the contraction rate slowed down due to slow evaporation of the solvent. Radial contraction shows the exponential decaying trend.

3.1. BET Analysis. The pore sizes (as determined by BET) of silica matrices (IL was extracted from the pores before making $\mathrm{N}_{2}$-sorption studies) corresponding to $65 \mathrm{wt} \%$ of IL (higher loading of IL was used intentionally, so that the effect of ultrasonic irradiation (if any), is significant) in the reaction vessel for \#IG, \#IG1, and \#IG2 are given in Table 1 . From Table 1, it can be seen that the pore parameter is maximum for \#IG2, that is, high power ultrasonic irradiation produces large pores; large pore size may be attributed to large cavitation bubbles formed due to high power ultrasonic irradiation (resulting a larger pores), while low power ultrasonication produces smaller cavitation bubbles (hence smaller pores). Ultrasonic irradiation increases pore volume as well as porosity, and the highest porosity is observed for sample \#IG2. However, ultrasonic irradiation decreases the surface area. IL-confined porous silica matrices were

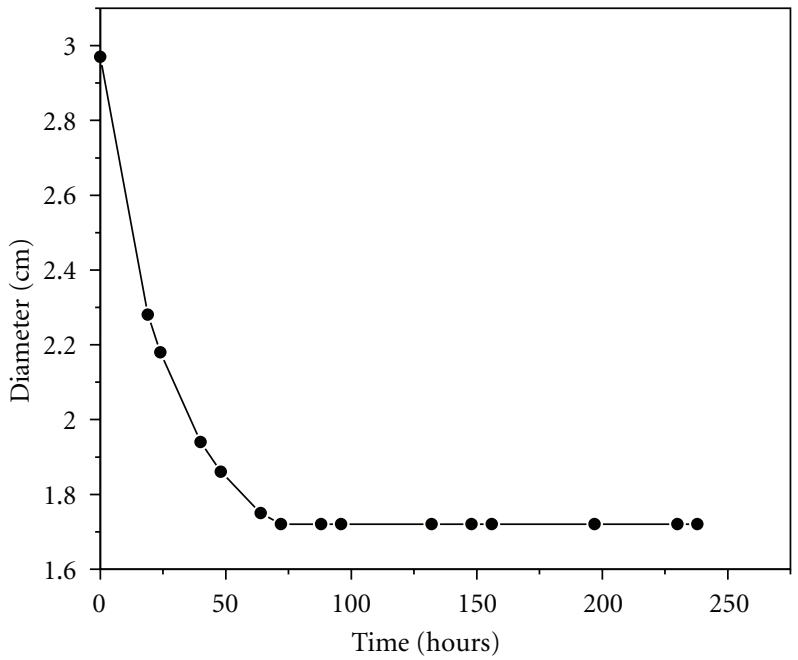

FIGURE 1: Radial contraction of disc shaped silica monolith ionogels (without ultrasonication).

obtained with (low and high power ultrasonic irradiation) and without ultrasonication, and corresponding isotherms and pore size distribution curves are shown in Figure 2. From Figure 2, it can be seen that there is sharp decline in the desorption curve which is indicative of mesoporosity, while the hysteresis between the two curves demonstrates that there is a diffusion bottleneck. Inset of Figure 2 shows pore size distribution curve, and from the curves it can be seen that the low power ultrasonic irradiation resulted in nearly uniform pore size distribution. $S_{\text {BET }}$ decreased by about $17 \%$ upon US irradiation; there was larger decrease corresponding to high power ultrasonic irradiation. Mass density of disk-shaped monolith was found to decrease upon ultrasonication.

The $\%$ porosity of the samples was calculated from $\mathrm{BJH}$ data using the following equation (1)

$$
\% \text { porosity, } \varphi=\frac{\mathrm{BJH} \text { pore volume }}{\mathrm{BJH} \text { pore volume }+1 / \rho} \text {, }
$$

where $\rho$ is the density of silica, $\left(2.2 \mathrm{~g} / \mathrm{cm}^{3}\right)$ [29]. The $\%$ porosity of the samples is given in the Table 1. It was found that ultrasonication resulted in change in porosity, high power ultrasonication resulted in larger change in porosity.

3.2. Change in the FTIR Bands of IL on Confinement. The FTIR spectra of unconfined (bulk), confined IL with low as well as high power are shown in Figure 3. Before taking any measurement, we heated the IL-confined samples in order to avoid the spurious peaks arising from residual solvent 
TABLE 2: Vibrational bands of IL ([BMIM] $\left[\mathrm{PF}_{6}\right]$ ) and IL-confined samples (\#IG, \#IG1, and \#IG2).

\begin{tabular}{lccc}
\hline & Vibrational bands $\left(\mathrm{cm}^{-1}\right)$ & & \\
Bulk IL & \#IG & 1098 & 1104 \\
\hline 1114 (in plane C-H bending of imidazolium ring) & $2881,2942,2969$ & $2881,2942,2970$ & $2881,2942,2969$ \\
$2880,2941,2968$ (alkyl chain C-H vibration) & 3128 & 3128 & 3128 \\
3127 (cation ring C-H vibration) & 3175 & 3174 & \\
$3172\left(\mathrm{C}_{2}-\mathrm{N}_{1}-\mathrm{C}_{5}\right.$ vibration) & & & 3174 \\
\hline
\end{tabular}

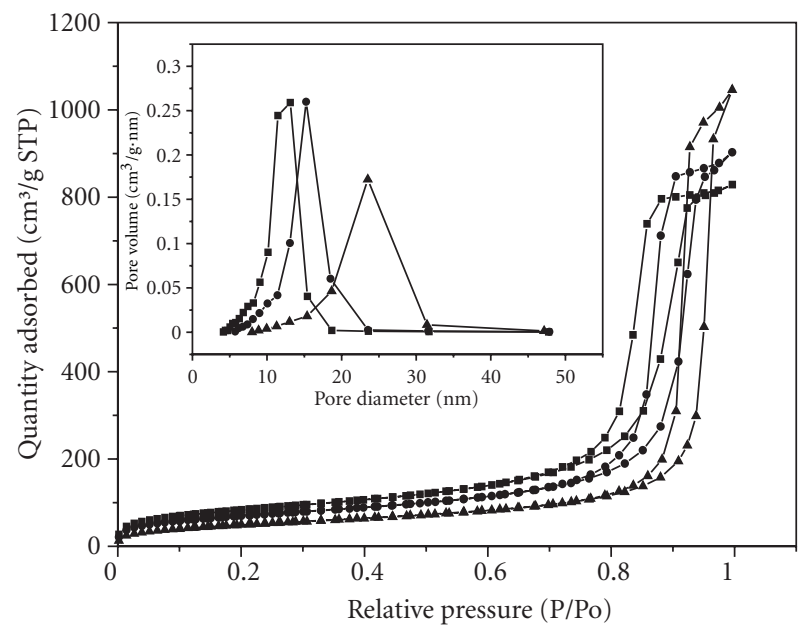

Figure 2: $\mathrm{N}_{2}$ adsorption-desorption isotherms and Pore-size distribution (inset) of silica gel matrices: \#IG $(\mathbf{\square})$, \#IG1 (•), \#IG2 (ム).

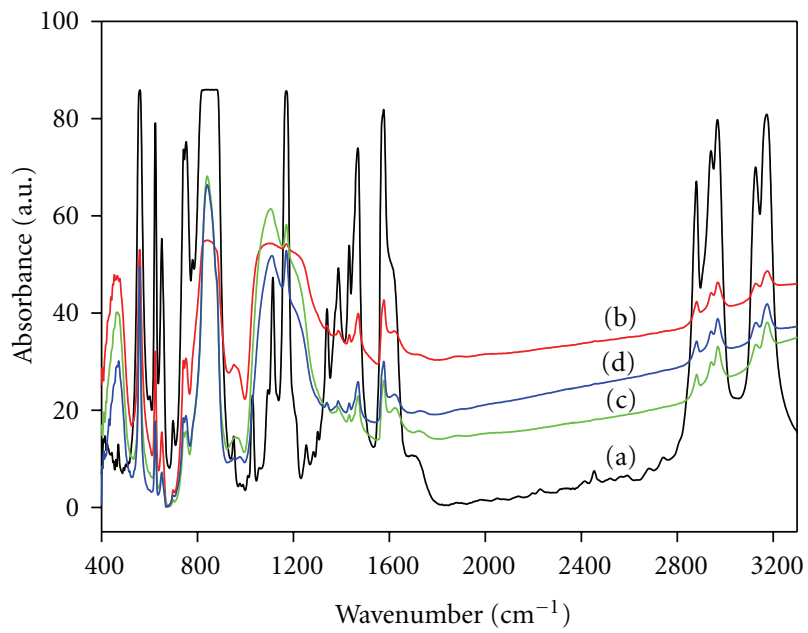

Figure 3: The FTIR spectra of (a) pure IL, (b) \#IG, (c) \#IG1, and (d) \#IG2.

left in the samples. The peaks of unconfined IL shift on confinement as given below.

(i) The vibrational band related to $\mathrm{PF}_{6}$ at $837 \mathrm{~cm}^{-1}$ of bulk IL is shifted to $841 \mathrm{~cm}^{-1}, 840 \mathrm{~cm}^{-1}$, and $841 \mathrm{~cm}^{-1}$ in samples \#IG, \#IG1, and \#IG2, respectively.

(ii) From Figure 4(a) and Table 2, it can be seen that vibrational bands of bulk IL at $1114 \mathrm{~cm}^{-1}$ related to in-plane $\mathrm{C}-\mathrm{H}$ bending of imidazolium ring shift to $1098 \mathrm{~cm}^{-1}, 1104 \mathrm{~cm}^{-1}$, and $1109 \mathrm{~cm}^{-1}$ in samples \#IG, \#IG1 \#IG2, respectively. There is larger shift corresponding to unradiated sample, while high power ultrasonic irradiation results in the least shift.

(iii) The alkyl chain C-H vibrations at $2880 \mathrm{~cm}^{-1}$, $2941 \mathrm{~cm}^{-1}$, and $2968 \mathrm{~cm}^{-1}$, \{see Figure $4(\mathrm{~b})$ and Table 2\} of unconfined IL shift to $2881 \mathrm{~cm}^{-1}$, $2942 \mathrm{~cm}^{-1}, \quad 2969 \mathrm{~cm}^{-1} ; \quad 2881 \mathrm{~cm}^{-1}, \quad 2942 \mathrm{~cm}^{-1}$, $2970 \mathrm{~cm}^{-1}$, and $2881 \mathrm{~cm}^{-1}, 2942 \mathrm{~cm}^{-1}, 2969 \mathrm{~cm}^{-1}$ in \#IG, \#IG1, and \#IG2, respectively. It is important to see that alkyl chain $\mathrm{C}-\mathrm{H}$ vibrations in the present study are not changing much.

(iv) The cation ring $\mathrm{C}-\mathrm{H}$ vibrations as well as $\mathrm{C}_{2}-\mathrm{N}_{1}-\mathrm{C}_{5}$ vibrations at $3127 \mathrm{~cm}^{-1}, 3172 \mathrm{~cm}^{-1}$ \{see Figure $4(\mathrm{~b})$ and Table 2\} shift to $3128 \mathrm{~cm}^{-1}, 3175 \mathrm{~cm}^{-1}$, $3128 \mathrm{~cm}^{-1}, 3174 \mathrm{~cm}^{-1}$ and $3128 \mathrm{~cm}^{-1}, 3174 \mathrm{~cm}^{-1}$, respectively, in \#IG, \#IG1, and \#IG2. The shift in these vibrational bands can be attributed to the interaction of $\mathrm{H}$ of the ring with the pore walls.

3.3. Thermal Stability. Figure 5 shows the thermogravimetric analysis curve of the bulk IL, low power ultrasonicated, high power ultrasonicated, and without ultrasonicated samples.

It is clear that thermal stability gets reduced upon ultrasonic irradiation. Thermal degradation starts at approximately $170^{\circ} \mathrm{C}$ for all the samples having confined IL. Confined ILs exhibits multistep degradation process. Thermal stability gets reduced upon ultrasonic irradiation. For low power ultrasonic irradiation, the onset of decomposition temperature, $T_{d}$, is $174^{\circ} \mathrm{C}$ while high power ultrasonic irradiation onset, $T_{D}$, is $177^{\circ} \mathrm{C}$.

3.4. Differential Scanning Calorimetry. DSC experiments disclose the effect of confinement on the phase transition of the ionic liquid within the ionogels. From the DSC thermogram (Figure 6) it can be seen that the glass transition temperature $\left(T_{g}\right)$ for the bulk IL $\left([\mathrm{BMIM}]\left[\mathrm{PF}_{6}\right]\right)$ is about $-75^{\circ} \mathrm{C}$ which becomes $-76.4^{\circ} \mathrm{C}$ for $\# \mathrm{IG} 2$ sample, while there is slight change in $T_{g}$ for samples \#IG1 and \#IG in comparison to \#IG2. Thus, the decrease in the glass transition temperature upon confinement of IL in sample $\# \mathrm{IG} 2$ is about $1.4^{\circ} \mathrm{C}$ while, in samples \#IG1 and \#IG, is $\sim 1^{\circ} \mathrm{C}$. The decrease in the glass transition temperature $\left(T_{g}\right)$ can be explained on the basis of the following equation [14]:

$$
\Delta T_{g}=\frac{V \Delta \alpha T_{g} 2 \Delta \sigma}{\Delta C_{p} R},
$$




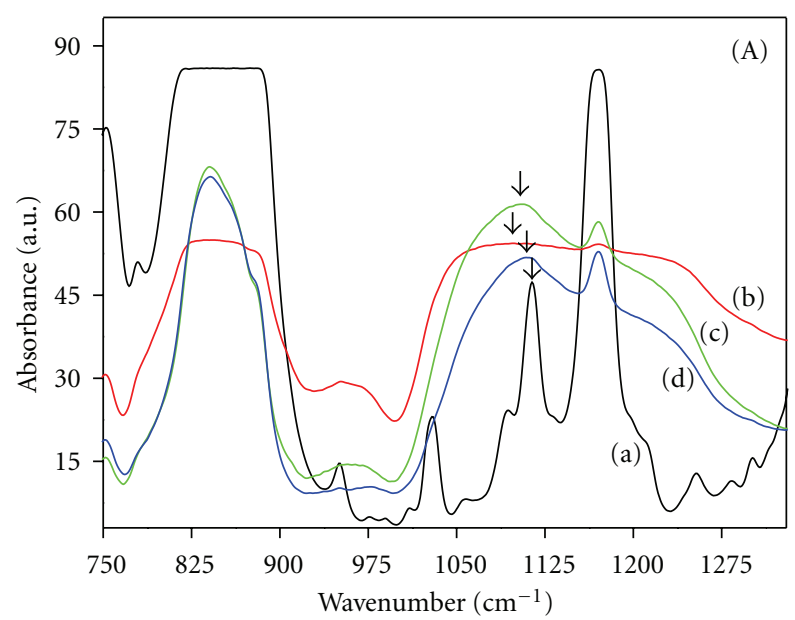

(a)

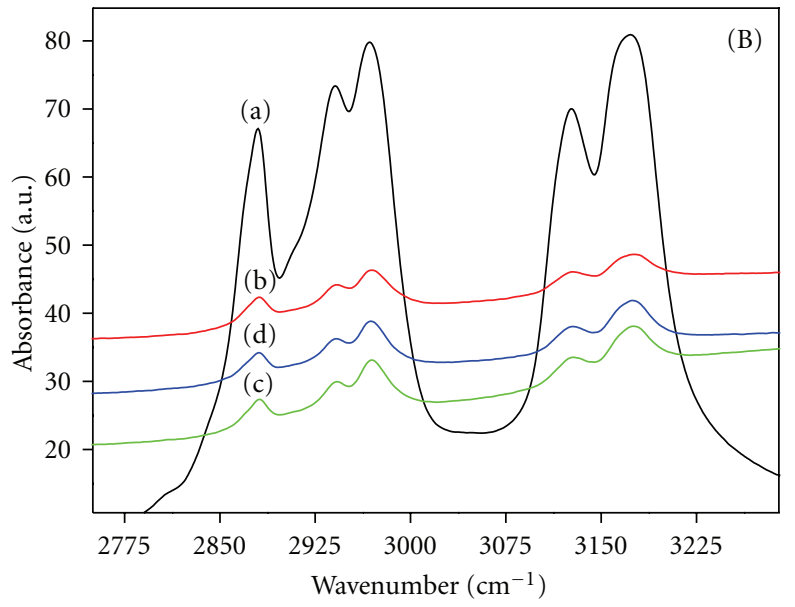

(b)

FIGURE 4: The extended FTIR spectra of $\mathrm{BMIMPF}_{6}$, before and after confinement in the regions (A) $750-1330 \mathrm{~cm}^{-1}$ and (B) $2750-3290 \mathrm{~cm}^{-1}$ for (a) pure IL, (b) \#IG, (c) \#IG1, and (d) \#IG2.

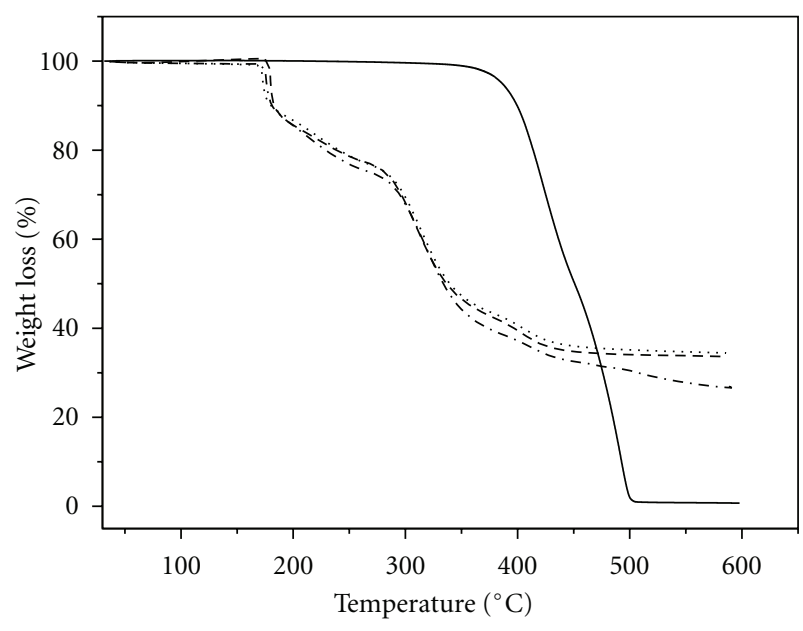

Figure 5: TGA thermograms for bulk IL $\left(\mathrm{BMIMPF}_{6}\right)(-)$, \#IG (- - - ), \#IG1 $(\cdots \cdots)$, and \#IG2 (- - - - ).

where $\Delta \alpha$ is the thermal expansion coefficient, $V$ is the molar volume, $\Delta \sigma$ is the difference between gas wall and ionic liquid wall interfacial energies, $T_{g}$ is the glass transition temperature of unconfined IL, and $\Delta C_{p}$ is the heat capacity at constant pressure. The above equation describes the relation between glass transition temperature and pore diameter $(d=$ $2 R$ ). However, quantitative explanation is difficult (because of complicated wall particle interaction).

\section{Conclusion}

Ionogels were prepared by both ultrasonic-assisted sol-gel process and traditional sol-gel process. It has been found that ultrasonic irradiation affects the gelation dynamics and kinetics and results in changes in pore parameters. We have also found a change in the glass transition temperature $\left(T_{g}\right)$ of the IL upon confinement. The result shows that ultrasonic

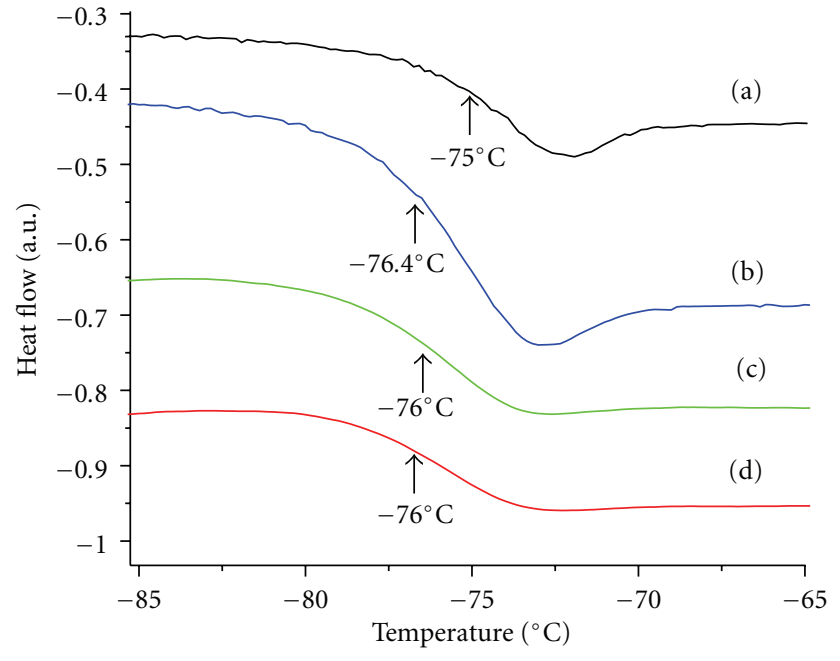

FIGURE 6: Glass transitions of (a) bulk IL (BMIMPF 6 ), (b) \#IG2, (c) \#IG1, and (d) \#IG.

irradiation produces changes in poreparameters, and pore size distribution becomes uniform.

\section{Acknowledgments}

R. K. Singh is grateful to the DST, New Delhi and BRNSDAE, India for providing financial assistance.

\section{References}

[1] M. Armand, F. Endres, D. R. MacFarlane, H. Ohno, and B. Scrosati, "Ionic-liquid materials for the electrochemical challenges of the future," Nature Materials, vol. 8, no. 8, pp. 621629, 2009.

[2] N. V. Plechkova and K. R. Seddon, "Applications of ionic liquids in the chemical industry," Chemical Society Reviews, vol. 37, no. 1, pp. 123-150, 2008. 
[3] F. Endres and S. Zein El Abedin, "Air and water stable ionic liquids in physical chemistry," Physical Chemistry Chemical Physics, vol. 8, no. 18, pp. 2101-2116, 2006.

[4] J. F. Wishart, "Energy applications of ionic liquids," Energy and Environmental Science, vol. 2, no. 9, pp. 956-961, 2009.

[5] L. A. Blanchard, D. Hancu, E. J. Beckman, and J. F. Brennecke, "Green processing using ionic liquids and $\mathrm{CO}_{2}$," Nature, vol. 398, no. 6731, pp. 28-29, 1999.

[6] K. R. Seddon, "Ionic liquids: a taste of the future," Nat Mater, vol. 2, no. 6, pp. 363-365, 2003.

[7] J. P. Hallett and T. Welton, "Room-temperature ionic liquids: solvents for synthesis and catalysis," Chemical Reviews, vol. 111, no. 5, pp. 3508-3576, 2011.

[8] S. Seki, Y. Kobayashi, H. Miyashiro et al., "Lithium secondary batteries using modified-imidazolium room-temperature ionic liquid," Journal of Physical Chemistry B, vol. 110, no. 21, pp. 10228-10230, 2006.

[9] R. F. de Souza, J. C. Padilha, R. S. Gonçalves, and J. Dupont, "Room temperature dialkylimidazolium ionic liquid-based fuel cells," Electrochemistry Communications, vol. 5, no. 8, pp. 728-731, 2003.

[10] A. Balducci, U. Bardi, S. Caporali, M. Mastragostino, and F. Soavi, "Ionic liquids for hybrid supercapacitors," Electrochemistry Communications, vol. 6, no. 6, pp. 566-570, 2004.

[11] P. Wang, S. M. Zakeeruddin, J. E. Moser, and M. Grätzel, "A new ionic liquid electrolyte enhances the conversion efficiency of dye-sensitized solar cells," Journal of Physical Chemistry B, vol. 107, no. 48, pp. 13280-13285, 2003.

[12] D. R. Macfarlane, M. Forsyth, P. C. Howlett et al., "Ionic liquids in electrochemical devices and processes: managing interfacial electrochemistry," Accounts of Chemical Research, vol. 40, no. 11, pp. 1165-1173, 2007.

[13] S. Dai, Y. H. Ju, H. J. Gao, J. S. Lin, S. J. Pennycook, and C. E. Barnes, "Preparation of silica aerogel using ionic liquids as solvents," Chemical Communications, no. 3, pp. 243-244, 2000.

[14] M. P. Singh, R. K. Singh, and S. Chandra, "Studies on imidazolium-based ionic liquids having a large anion confined in a nanoporous silica gel matrix," Journal of Physical Chemistry B, vol. 115, no. 23, pp. 7505-7514, 2011.

[15] J. Le Bideau, L. Viau, and A. Vioux, "Ionogels, ionic liquid based hybrid materials," Chemical Society Reviews, vol. 40, no. 2, pp. 907-925, 2011.

[16] K. S. W. Sing, D. H. Everett, R. A. W. Haul et al., "Reporting physisorption data for gas/solid systems with special reference to the determination of surface area and porosity (recommendations 1984)," Pure and Applied Chemistry, vol. 57, no. 4, pp. 603-619, 1985.

[17] M. Davenport, A. Rodriguez, K. J. Shea, and Z. S. Siwy, "Squeezing ionic liquids through nanopores," Nano Letters, vol. 9, no. 5, pp. 2125-2128, 2009.

[18] R. Göbel, A. Friedrich, and A. Taubert, "Tuning the phase behavior of ionic liquids in organically functionalized silica ionogels," Dalton Transactions, vol. 39, no. 2, pp. 603-611, 2010.

[19] S. Chen, K. Kobayashi, Y. Miyata et al., "Morphology and melting behavior of ionic liquids inside single-walled carbon nanotubes," Journal of the American Chemical Society, vol. 131, no. 41, pp. 14850-14856, 2009.

[20] M. P. Singh, R. K. Singh, and S. Chandra, "Thermal stability of ionic liquid in confined geometry," Journal of Physics D: Applied Physics, vol. 43, no. 9, Article ID 092001, 2010.

[21] A. Karout and A. C. Pierre, "Silica xerogels and aerogels synthesized with ionic liquids," Journal of Non-Crystalline Solids, vol. 353, no. 30-31, pp. 2900-2909, 2007.
[22] O. Oter, K. Ertekin, and S. Derinkuyu, "Photophysical and optical oxygen sensing properties of tris(bipyridine)ruthenium(II) in ionic liquid modified sol-gel matrix," Materials Chemistry and Physics, vol. 113, no. 1, pp. 322-328, 2009.

[23] M. Sha, G. Wu, Y. Liu, Z. Tang, and H. Fang, "Drastic phase transition in ionic liquid [ $\mathrm{dmim}][\mathrm{cl}]$ confined between graphite walls: new phase formation," Journal of Physical Chemistry C, vol. 113, no. 11, pp. 4618-4622, 2009.

[24] A. Karout and A. C. Pierre, "Porous texture of silica aerogels made with ionic liquids as gelation catalysts," Journal of SolGel Science and Technology, vol. 49, no. 3, pp. 364-372, 2009.

[25] M. P. Singh, R. K. Singh, and S. Chandra, "Properties of ionic liquid confined in porous silica matrix," ChemPhysChem, vol. 11, no. 9, pp. 2036-2043, 2010.

[26] K. Morita, Y. Hu, and J. D. Mackenzie, "The effects of ultrasonic irradiation on the preparation and properties of Ormosils," Journal of Sol-Gel Science and Technology, vol. 3, no. 2, pp. 109-116, 1994.

[27] E. Blanco, L. Esquivias, R. Litrán, M. Piñero, M. Ramírez-delSolar, and N. de la Rosa-Fox, "Sonogels and derived materials," Applied Organometallic Chemistry, vol. 13, no. 5, pp. 399-418, 1999.

[28] L. Esquivias, M. Piñero, V. Morales-Flórez, and N. de la RosaFox, "Aerogels synthesis by sonocatalysis: sonogels," in Aerogels Handbook, M. A. Aegerter, N. Leventis, and M. M. Koebel, Eds., pp. 419-441, 1st edition, 2011.

[29] R. K. Iler, The Chemistry of Silica, Wiley, New York, NY, USA, 1979. 

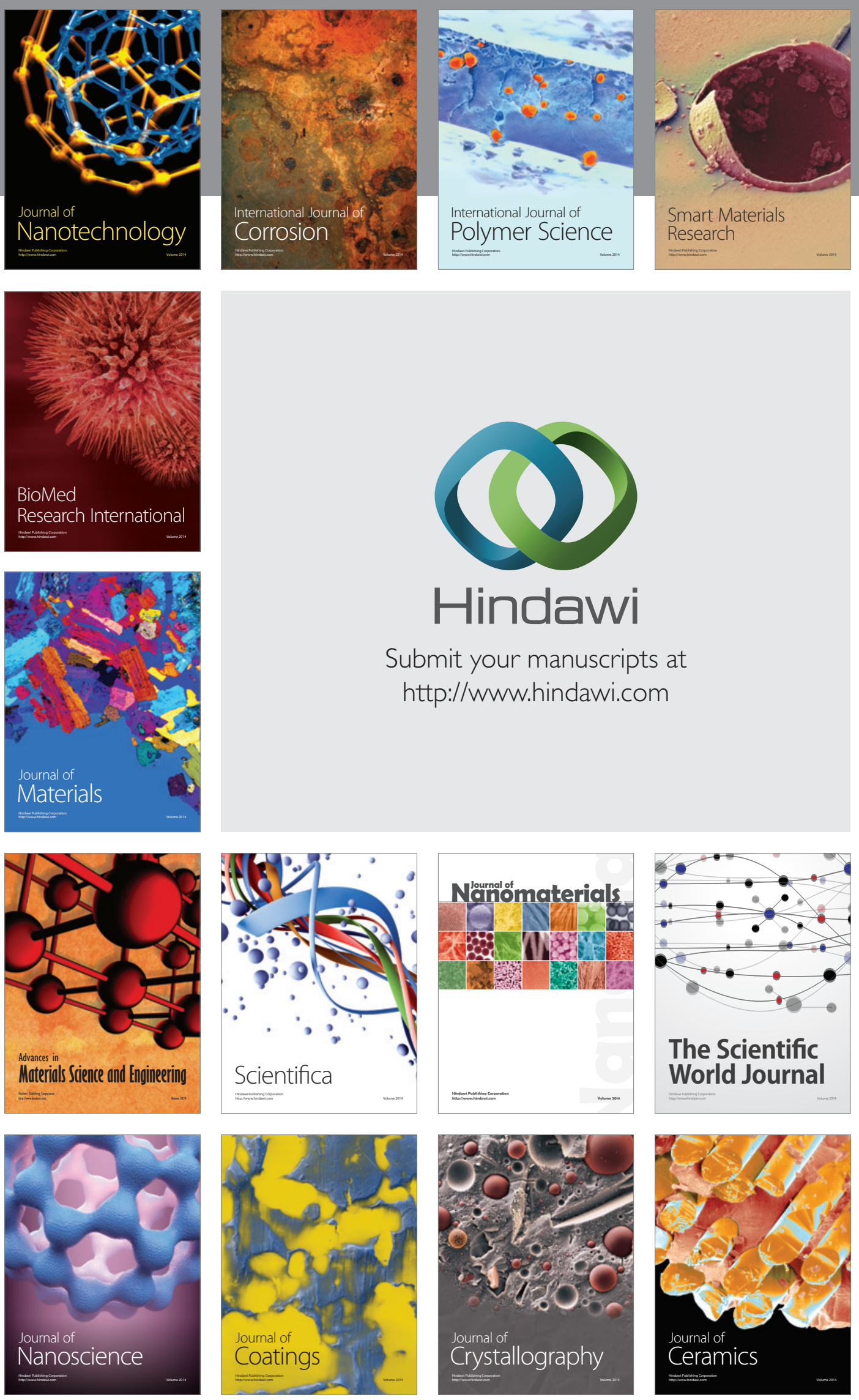

The Scientific World Journal

Submit your manuscripts at

http://www.hindawi.com

\section{World Journal}

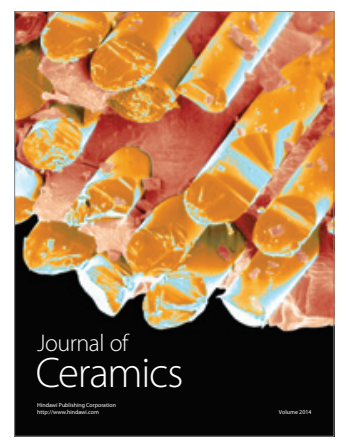

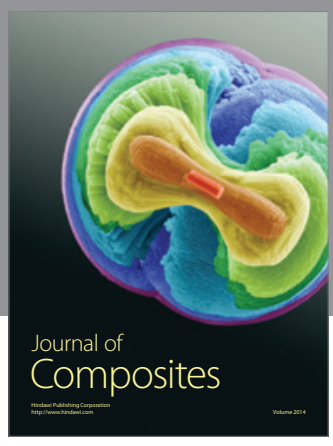
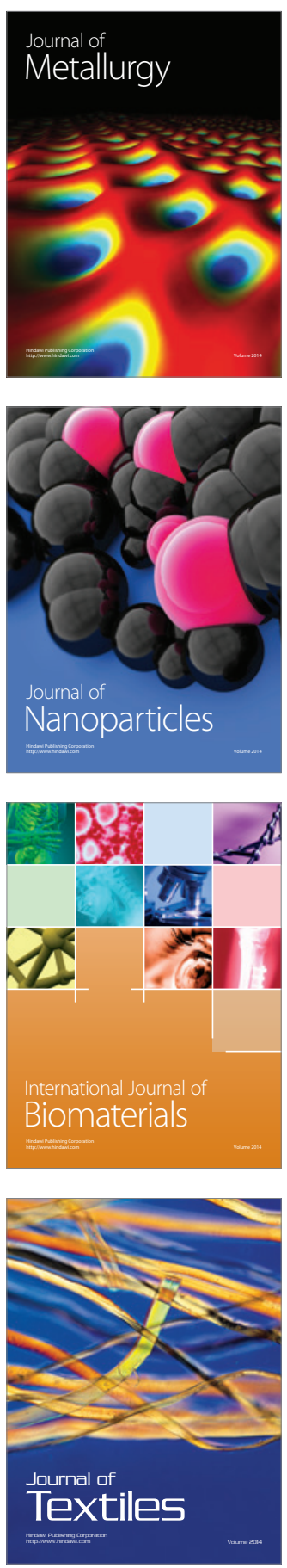